\title{
A Comunicação Preliminar entre Breuer e Freud: uma tradução comentada
}

Preliminary Statement between Breuer and Freud: a commented translation

\author{
Trad. André Medina Carone*
}

\begin{abstract}
We present a new translation of Breuer's and Freud's "Preliminary Statement", followed by notes and comments with the purpose of broadening the debate over the translation of Freud's work into the Portuguese language.
\end{abstract}

Key-Words: Freud; Breuer, Preliminary Statement, Translation

Resumo: Apresentamos uma nova tradução da "Comunicação Preliminar" de Sigmund Freud e Josef Breuer, seguida por comentários que visam ampliar a discussão sobre a tradução das obras de Freud para o português.

Palavras-chave: Freud, Breuer, Comunicação Preliminar, Tradução

\section{Introdução do tradutor}

Ao oferecer esta tradução do capítulo de abertura dos Estudos sobre histeria, espero contribuir para o novo momento da recepção das obras de Freud que teve início com sua passagem ao domínio público em língua portuguesa em 2010. Além de apresentar uma versão realizada a partir do original alemão ${ }^{1}$, desejo oferecer uma discussão

\footnotetext{
* Professor do Departamento de Filosofia da EFLCH/UNIFESP. Email: andremedinacarone@gmail.com

${ }^{1}$ A única tradução brasileira atualmente disponível dos Estudos sobre histeria toma por base a tradução inglesa de James Strachey e não o texto original. (FREUD 1990).
} 


\section{Freud/Trad. Carone - Comunicação Preliminar}

sobre certos aspectos da elaboração do artigo, e assim abrir a sugestões e críticas dos leitores o projeto de uma tradução integral dos Estudos sobre histeria ${ }^{2}$.

Redigido em 1892 e publicado no ano seguinte por Josef BREUER e Sigmund FREUD, o artigo "Sobre o mecanismo psíquico dos fenômenos histéricos" - mais conhecido pelo subtítulo, "Comunicação Preliminar" - vem à luz em meio a uma investigação: ele não representa o primeiro passo de um estudo a ser realizado, como comprova a repetida evocação das origens do próprio trabalho, menos ainda o encerramento de uma pesquisa. Embora anunciem que seus estudos apenas tornaram mais próxima a compreensão do mecanismo da histeria, Breuer e Freud não evitam definições abrangentes como "o histérico sofre predominantemente de reminiscências", por exemplo. Para reproduzir a região intermediária a partir da qual os dois médicos se pronunciam era necessário dar valor às oscilações que se manifestam no texto, mantendo abertas as lacunas e contradições internas que tornam o texto vivo e pleno de interesse.

Tanto quanto possível, procurei preservar a hesitação e o inacabamento que marcam este estágio das teorizações de Freud e de Breuer - muito distintas uma da outra, como ambos admitem. Suas incertezas se manifestam na recorrência das orações coordenadas independentes (experiências que "faltam à memória do paciente em seu estado psíquico comum ou comparecem ali em termos os mais sumários") e das sobreposições de complementos ou sujeitos compostos em uma mesma oração ("afetos penosos do temor, da angústia, da dor psíquica”; ou "a recordação dos eventos subsequentes, o amparo, a percepção da segurança no presente”). No lugar de um esquema teórico bem concatenado, eles se valem de generalizações parciais $e$ cautelosas nas quais sobressai o recuo dos efeitos às causas. Este percurso indutivo justifica a escolha de um vocabulário compatível com o movimento de suas descobertas: assim, dei preferência a "evento" (no lugar de "processo") para Vorgang, termo que se ajusta melhor à caracterização do trauma psíquico como um acontecimento intolerável para a consciência normal. Também pareceram mais apropriados a este procedimento indutivo o verbo "inferir" (em vez de "concluir")

\footnotetext{
${ }^{2}$ Outros dois capítulos do livro (os casos clínicos de Anna O. e Miss Lucy) serão publicados em revistas acadêmicas até o final de 2012.
} 


\section{Freud/Trad. Carone - Comunicação Preliminar}

para schliessen, ou "eficaz" e "efeito" como equivalentes para wirksam $e$ Wirkung, no lugar de “ativo" e "ação". De resto, estas formulações não são de modo algum estranhas para a investigação médica, à qual este trabalho permanece vinculado apesar de sua importância para o surgimento da psicanálise.

Em uma investigação tateante, na qual os autores procuram explicar de um só golpe os fenômenos que observam e os termos que utilizam para explicá-los, não devem causar surpresa as sucessivas restrições ao alcance de cada afirmação ou às circunstâncias de observação, as quais reproduzi em todos os casos: "em geral”, "com frequência”, "em um grande número de casos", "circunstâncias que se apresentaram para nós", são expressões que foram resguardadas mesmo quando pareciam reincidentes ou incômodas ao ouvido do leitor. Apesar do tom irregular e por vezes áspero da exposição, nada nos impede de apreciar o texto como o início de uma aventura arriscada para a qual estes dois médicos estão menos equipados do que poderiam supor. As notas à tradução, separadas ao final do texto, trazem complementos ou informações para quem cultive a curiosidade pelo texto original ou pelas preferências do tradutor, mas não pretendem servir como roteiro em uma aventura que o leitor pode realizar por sua própria conta.

André Medina Carone,

agosto de 2012 


\title{
Sobre o mecanismo psíquico dos fenômenos histéricos $^{i}$
}

\section{(Comunicação Preliminar)}

\author{
Dr. Josef Breuer e Dr. Sigmund Freud,
} em Viena

Impelidos por uma observação acidental, desde alguns anos buscamos nas formas e nos sintomas mais variados de histeria pela causa precipitadora ${ }^{\text {ii }}$, pelo evento que fez surgir o fenômeno em questão pela primeira vez, com frequência vários anos antes. Na ampla maioria dos casos, não se consegue estabelecer esse ponto de partida pelo exame clínico, mesmo que detalhado; em parte por tratar-se muitas vezes de experiências cuja comunicação traz desconforto aos pacientes, mas sobretudo porque eles de fato não o recordam, e muitas vezes não suspeitam da conexão causal entre o evento precipitador e o fenômeno patológico. Em geral é necessário hipnotizar o paciente e evocar na hipnose as lembranças do período no qual o sintoma apareceu pela primeira vez, e então se consegue expor aquela conexão da maneira mais clara e persuasiva.

Em um grande número de casos este método de investigação nos proporcionou resultados que parecem estimáveis tanto em termos práticos como teóricos.

Em termos teóricos, pois ele nos provou que o fator acidental é determinante para a patologia da histeria em um grau superior ao qual é conhecido e admitido. Que na histeria "traumática" ele seja o acidente que provocou a síndrome é algo evidente, e se nos ataques histéricos pode-se inferir das declarações dos pacientes que eles voltam 


\section{Freud/Trad. Carone - Comunicação Preliminar}

sempre a alucinar o evento que produziu o primeiro ataque, também aqui a conexão causal é muito clara. Em outros fenômenos a situação é mais obscura.

Porém nossas experiências nos mostraram que os mais diversos sintomas considerados como produções espontâneas, por assim dizer idiopáticas da histeria, encontram-se tão estritamente conectados ao trauma que os ocasionaram como os fenômenos já mencionados, nos quais a conexão é transparente. Pudemos remeter a estes eventos precipitadores neuralgias, bem como anestesias as mais diversas e que, em vários casos, persistiram por muitos anos; contraturas e paralisias; ataques histéricos e convulsões epileptoides que todos os observadores tomavam por genuína epilepsia; petit mal e afecções assemelhadas a tiques; vômitos persistentes e anorexias que chegavam à recusa de alimento; as mais variadas perturbações visuais, alucinações visuais recorrentes, etc. A desproporção entre a longa duração do sintoma histérico e a ocorrência única que o causou é a mesma que nos acostumamos a encontrar com regularidade na neurose traumática; muito frequentemente são acontecimentos da infância que produziram um sintoma mais ou menos severo, o qual persiste pelos anos seguintes.

Muitas vezes a conexão é tão clara que se torna perfeitamente visível por que o incidente precipitador gerou este fenômeno e nenhum outro. Ele está, portanto, determinado da maneira mais clara pela causa precipitadora. Para tomar o exemplo mais banal: um afeto penoso, que surge durante uma refeição, mas é recalcado, ${ }^{\text {iii }}$ e depois provoca náusea e vômitos, que perduram por meses como vômitos histéricos. Uma moça atormentada pela angústia, em vigília ao lado do leito de um doente, cai em estado crepuscular e tem uma alucinação aterradora, enquanto seu braço direito, caído sobre o encosto da poltrona, está dormente; forma-se aqui uma paresia deste braço com contratura e anestesia. Ela quer rezar e não encontra palavras; consegue por fim pronunciar uma oração para crianças em inglês. Posteriormente, quando uma histeria grave e de extrema complexidade se desenvolve, ela fala, escreve e compreende apenas o inglês, sem compreender a língua materna por um ano e meio. - Uma criança muito doente finalmente adormece, a mãe faz o possível para permanecer em silêncio e não acordá-la; mas justamente por conta deste propósito (“contra-vontade histérica!”), emite com a língua um ruído de estalo. O estalo se repete depois em outra ocasião, na qual ela 


\section{Freud/Trad. Carone - Comunicação Preliminar}

também queria permanecer em silêncio absoluto, e dali forma-se um tique, um estalo de língua que acompanha os estados de agitação. Um homem dos mais inteligentes acompanha o irmão, cujo quadril ancilosado é estendido sob o efeito de anestesia. No instante em que a articulação cede com o som de um estalido, ele sente em seu quadril uma dor violenta que persiste por quase um ano, etc.

Em outros casos a conexão não é tão simples; existe apenas uma ligação que se poderia designar como simbólica entre a causa precipitadora e o fenômeno patológico, como aquela que a pessoa saudável forma nos sonhos ou, por exemplo, quando uma dor psíquica se acrescenta a uma neuralgia, ou o vômito ao afeto de repugnância moral. Estudamos pacientes que faziam o uso mais amplo desta simbolização. - Há ainda outros casos nos quais de início esta determinação está vedada ao entendimento; incluem-se entre eles os sintomas histéricos típicos, como hemianestesia, estreitamento do campo visual, convulsões epileptiformes, etc. Reservamos a apresentação de nossos pontos de vista a respeito deste grupo para uma discussão mais detalhada da questão.

Estas observações nos parecem comprovar a analogia entre a patogênese da histeria comum e da neurose traumática e justificar uma extensão do conceito de “histeria traumática”. Na neurose traumática a causa eficaz da doença não é a lesão corporal, sequer a mais leve, e sim o afeto atemorizante, o trauma psíquico. De modo análogo nossa investigação infere para diversos, se não para todos os principais sintomas histéricos, circunstâncias que merecem ser designadas como traumas psíquicos. Todas as experiências que produzem os afetos penosos do temor, da angústia, da vergonha, da dor psíquica podem atuar como traumas psíquicos e, como é evidente, depende da sensibilidade de cada pessoa (bem como de outra condição a ser mencionada adiante) se a experiência irá adquirir o valor de um trauma. Na histeria comum não é raro que no lugar do grande trauma compareçam diversos traumas parciais, circunstâncias agrupadas, que apenas por somatória poderiam exercer uma ação traumática, e que estão vinculados na medida em que formam parcelas de uma história de sofrimento. Em outros casos são circunstâncias aparentemente indiferentes que, por coincidirem com um acontecimento realmente eficaz ou com algum momento de estimulação inusual, conquistaram como traumas uma dignidade que, do contrário, 


\section{Freud/Trad. Carone - Comunicação Preliminar}

não seria possível lhes atribuir, e que no entanto elas preservam a partir daquele momento.

Mas a conexão causal entre o trauma psíquico precipitador e o fenômeno histérico não é de uma espécie que faz do trauma o agent provocateur que acionaria o sintoma - o qual, conquistando independência, subsistiria por si próprio. Devemos afirmar, pelo contrário, que o trauma psíquico, ou a recordação deste trauma, age à maneira de um corpo estranho, que deve ser reconhecido como o agente eficaz muito tempo após sua penetração, e nós encontramos a prova deste fato em um fenômeno extremamente incomum que concede igualmente às nossas descobertas um interesse prático considerável.

Descobrimos, de início para a nossa maior surpresa, que cada sintoma histérico desaparecia imediata e definitivamente se a recordação do evento precipitador fosse despertada com plena transparência, evocando com ela o afeto concomitante, e se o paciente em seguida retratasse o evento da forma mais detalhada possível e desse palavra ao afeto. A recordação sem afeto quase sempre é totalmente ineficaz; é necessário que o processo psíquico transcorrido na origem seja repetido com toda a vivacidade possível, recuperado in statum nascendi e depois "eliminado pela fala ${ }^{\mathrm{i} v}$ ". Assim ressurgem espasmos, neuralgias, alucinações - quando se trata de fenômenos ligados a estímulos - com plena intensidade, e depois desaparecem para sempre. Insuficiências funcionais, paralisias e anestesias desaparecem igualmente, sem que sua intensificação momentânea se tornasse nítida ${ }^{3}$.

Seria o caso de suspeitar que se trata de uma sugestão involuntária: o paciente espera ser libertado de sua aflição pelo procedimento, e o fator eficaz seria esta expectativa, e não a eliminação pela fala. Mas as coisas não se passam desse modo: a primeira observação do gênero, na qual uma histeria extremamente complicada foi analisada e os sintomas causados separadamente foram separadamente suprimidos,

\footnotetext{
${ }^{3}$ Delboeuf e Binet admitiam claramente a viabilidade de uma terapia desta natureza, como atestam as citações que seguem: "Explicaremos agora de qual modo o magnetizador contribui para a cura. Ele coloca o sujeito no estado em que a doença se manifestou, e combate por meio da palavra esta mesma doença, mas renascida". - Binet, As alterações da personalidade. 1892, p. 243: “...talvez vejamos que ao dirigirse ao doente por um artifício mental, no instante em que o sintoma surgiu pela primeira vez, tornamos o doente mais dócil a uma sugestão curativa". - No interessante livro de P. Janet: $O$ automatismo psicológico, Paris, 1889, encontra-se a descrição da cura de uma moça histérica, alcançada pela aplicação de um procedimento análogo ao nosso.
} 


\section{Freud/Trad. Carone - Comunicação Preliminar}

procede do ano de 1881 - portanto, de um período "pré-sugestivo"; ela foi proporcionada pela auto-hipnose espontânea da paciente e surpreendeu seu observador.

Invertendo a sentença cessante causa cessat effectus, certamente podemos inferir destas observações que, passados os anos, o evento precipitador continua a atuar de alguma maneira - não indiretamente, pela transmissão em uma cadeia de termos intermediários, e sim diretamente como causa ativa, a exemplo de uma dor psíquica, recordada com a consciência desperta, que continua a provocar a secreção lacrimal em um período ulterior: $o$ histérico sofre predominantemente de reminiscências ${ }^{4}$.

De início parece estranho que experiências vividas há tanto tempo devam atuar tão intensamente - que a recordação destas experiências não deva sujeitar-se ao desgaste ${ }^{\mathrm{v}}$ ao qual por fim vemos ceder todas as nossas recordações. Talvez compreendamos melhor estes fatos com o auxílio das seguintes considerações.

O desbotamento ou desaparecimento do afeto de uma recordação depende de vários fatores. Tem grande importância neste caso se houve ou não uma reação enérgica ao acontecimento afetante. Por reação compreendemos toda a série de reflexos voluntários e involuntários nos quais, como mostra a experiência, o afeto é eliminado: do choro ao ato da vingança. Se a reação ocorre em medida suficiente, desaparece uma grande parcela do afeto; nossa linguagem comprova este fato da observação cotidiana pelas expressões "botar tudo para fora", "aliviar o peito ${ }^{\mathrm{vi},}$, e outras. Se a reação é recalcada, o afeto permanece ligado à recordação. Uma agressão que foi revidada, mesmo que só com palavras, é recordada de modo diferente daquela agressão que precisou ser consentida. A linguagem também reconhece a diferença entre as consequências psíquicas e corporais e, de modo peculiar, designa o sofrimento tolerado em silêncio como "injúria vii", A reação da pessoa lesada perante o trauma só possui de fato um efeito "catártico" pleno se for uma reação adequada; é o caso da vingança. Mas

\footnotetext{
${ }^{4}$ No texto desta comunicação preliminar não podemos separar o que é novo em seu conteúdo daquilo que já se encontra em outros autores como Möbius e Strümpell, que sustentam pontos de vista similares a respeito da histeria. Encontramos a principal afinidade com nossas elaborações teóricas e terapêuticas em observações circunstanciais publicadas por Benedikt, das quais nos ocuparemos em outra parte.
} 


\section{Freud/Trad. Carone - Comunicação Preliminar}

o homem encontra na linguagem um substituto para o ato, com auxílio do qual o afeto também poderá ser quase igualmente "ab-reagido”. Em outros casos a fala é o próprio reflexo adequado, como queixa e desabafo para a dor de um segredo (confissão!). Quando um reação deste tipo não se dá por ato, palavras ou nos casos mais simples pelo choro, a recordação do incidente preserva a tonalidade afetiva.

Entretanto a "ab-reação" não é o único modo de resolução disponível para o mecanismo psíquico normal da pessoa sadia quando ela sofre um trauma psíquico. Mesmo se não for ab-reagida, a recordação deste trauma ingressa no grande complexo de associação ${ }^{\text {viii }}$, posiciona-se ao lado de outras experiências que talvez a contradigam, é corrigida por outras ideias. Após um acidente, por exemplo, à recordação do perigo e à repetição (atenuada) do susto acrescenta-se a recordação dos eventos subsequentes, o amparo, a percepção da segurança no presente. A recordação de uma injúria é corrigida pela retificação dos fatos, pela consideração da autoestima, etc., e assim a pessoa normal consegue dar fim ao afeto concomitante por meio da atividade de associação.

Segue-se então aquela dissolução abrangente das impressões, aquele empalidecimento das recordações que denominamos "esquecimento", e que desgasta sobretudo as ideias que já não possuem eficácia afetiva.

Resulta de nossas investigações que aquelas recordações que se transformaram em causas precipitadoras de fenômenos histéricos preservaram-se com extraordinário frescor e toda sua intensidade afetiva por um longo período. Mas devemos mencionar o fato incomum, a ser avaliado logo adiante, de que os pacientes não dispõem destas recordações como de outras recordações de sua vida. Ao contrário, estas experiências faltam à memória do paciente em seu estado psíquico comum ou comparecem ali em termos os mais sumários. Somente quando se interroga o paciente sob hipnose estas recordações se apresentam com vivacidade plena.

Dessa maneira, durante seis meses uma de nossas pacientes reproduziu sob hipnose tudo o que a perturbara naquele mesmo dia do ano anterior (durante uma histeria aguda) com vivacidade alucinatória; um diário da mãe, o qual ela desconhecia, atestou a correção irrepreensível da reprodução. Outra paciente reviveu com nitidez alucinatória - em parte sob hipnose, em parte em ataques espontâneos - todos os eventos de uma psicose histérica vivida há dez anos, da qual ela predominantemente não 


\section{Freud/Trad. Carone - Comunicação Preliminar}

se recordava até o momento de sua reaparição. Ela trazia ainda recordações isoladas de grande valor etiológico em perfeita preservação e com nitidez sensorial, datadas de quinze a vinte e cinco anos, e que ao retornar produziam efeitos com toda a intensidade afetiva de novas experiências.

A razão para isso só pode ser buscada no fato de tais recordações constituírem uma exceção em todas as relações com o desgaste que foram mencionadas. Nota-se, com efeito, que estas recordações correspondem a traumas que não haviam sido suficientemente "ab-reagidos", e um exame apurado das razões que impediram a abreação nos faz descobrir ao menos duas séries de condições nas quais a reação ao trauma não acontece.

Atribuímos ao primeiro grupo os casos nos quais os pacientes não reagiram a traumas psíquicos porque a natureza do trauma impedia uma reação, como na perda aparentemente insubstituível de uma pessoa amada; ou porque as relações sociais tornavam impossível a reação, ou porque tratava-se de algo que o paciente queria esquecer, de algo que ele intencionalmente reprimia, inibia e recalcava de seu pensamento consciente ${ }^{\mathrm{ix}}$. A seguir encontramos na hipnose precisamente tais acontecimentos penosos como o fundamento dos fenômenos histéricos (delírios histéricos de santos e freiras, de mulheres abstinentes, de crianças de boa criação).

A segunda série de condições não é determinada pelo conteúdo das recordações, e sim pelos estados psíquicos com os quais coincidiram, nos pacientes, as experiências em questão. Como causa precipitadora de sintomas histéricos encontramos igualmente ideias que, em si mesmas inexpressivas, devem sua preservação ao fato de terem surgido ou sob fortes afetos paralisantes, como por exemplo o pavor, ou diretamente sob estados psíquicos anormais, como o estado crepuscular semi-hipnótico do devaneio, sob auto-hipnose, etc. Nestes casos é a natureza destes estados que impossibilitava uma reação frente ao acontecido.

Ambas as condições podem naturalmente coincidir e de fato coincidem com frequência. É o que se passa quando um trauma, em si eficiente, ocorre em um estado de consciência alterada ou de afeto intenso e paralisante; mas também parece acontecer com muitas pessoas que o trauma psíquico produza alguns destes estados anormais, que por sua vez tornam inviável a reação. 


\section{Freud/Trad. Carone - Comunicação Preliminar}

Entretanto é comum a estes dois grupos que os traumas psíquicos que não foram solucionados pela reação evitem igualmente a resolução pela elaboração associativa. No primeiro grupo trata-se do propósito do paciente, que deseja esquecer o acontecimento doloroso e o exclui da associação o quanto possível; no segundo grupo esta elaboração associativa fracassa por não existir uma rica conexão associativa entre o estado de consciência normal e o estado patológico no qual surgiram estas ideias. Em breve teremos oportunidade de examinar melhor estas circunstâncias.

É possível afirmar, portanto, que as ideias que se tornam patógenas preservam todo o seu frescor e força afetiva porque foi negado a elas o desgaste normal pela abreação e pela reprodução em estados de associação sem inibição.

III

Quando informamos quais as condições - determinantes, de acordo com nossas experiências - para que fenômenos histéricos se formassem a partir de traumas psíquicos, foi necessário falar sobre os estados anormais de consciência nos quais emergem tais ideias e destacar o fato de que não se deve buscar a recordação do trauma psíquico eficaz na memória normal do paciente, e sim na memória do hipnotizado. Quanto mais nos ocupávamos deste fenômeno, mais firme tornava-se esta nossa convicção: a cisão da consciência, tão evidente nos famosos casos clássicos como double conscience, está presente de forma rudimentar em toda histeria, e a inclinação a esta dissociação, e por consequência à aparição de fenômenos anormais de consciência (a qual denominaremos "hipnoide") é o fenômeno elementar desta neurose. Neste ponto nossa concepção coincide com a de Binet e de ambos os Janet, cujas notáveis descobertas com pacientes anestesiados faltam à nossa experiência.

Assim, ao lado da sentença frequentemente citada: "a hipnose é uma histeria artificial", gostaríamos de propor outra: a existência de estados hipnoides é o fundamento e condição para a histeria. A despeito de toda diversidade, estes estados hipnoides concordam entre si e com a hipnose em um ponto: as ideias que emergem neles são muito intensas mas estão bloqueadas do contato associativo com o conteúdo restante da consciência. Entre si estes estados hipnoides podem se associar, e por esta 


\section{Freud/Trad. Carone - Comunicação Preliminar}

via seu conteúdo ideativo pode alcançar graus diversos de organização psíquica. No mais, a natureza destes estados e o grau de seu isolamento com relação aos processos conscientes poderia igualmente variar, como vemos na hipnose, que abarca desde a leve sonolência até o sonambulismo, da recordação plena até a absoluta amnésia.

Se existirem estados hipnoides antes do adoecimento manifesto, eles oferecem então o terreno no qual o afeto assenta a recordação patógena ${ }^{\mathrm{x}}$ com suas posteriores manifestações somáticas. Este quadro corresponde à histeria por disposição. Mas nossas investigações mostram que um trauma severo (como o da neurose traumática), um intenso recalque (por exemplo, do afeto sexual), também podem efetuar uma cisão entre grupos de ideias em uma pessoa livre sob outros aspectos: este seria o mecanismo da histeria adquirida por via psíquica. Entre os extremos de ambas as formas é necessário reconhecer uma série na qual a propensão de um determinado indivíduo para a dissociação e a magnitude afetiva do trauma variam em proporção inversa.

Não temos nada de novo a dizer sobre o que fundamenta os estados hipnoides por disposição. Devemos acreditar que eles muitas vezes se desenvolvem a partir dos "sonhos diurnos", comuns até mesmo em pessoas saudáveis, e para os quais os trabalhos manuais femininos, por exemplo, oferecem tantas ocasiões. A questão de saber por que as "associações patológicas" formadas nestes estados são tão firmes e influenciam os processos somáticos com uma força muito superior a que estamos acostumados a encontrar em ideias coincide com o problema da eficácia da sugestão hipnótica em geral. Quanto a isso, nossas experiências nada trazem de novo; em contrapartida, elas lançam à luz a contradição entre a sentença: "a histeria é uma psicose" e o fato de que se pode encontrar, entre os histéricos, pessoas com a maior clareza de espírito, tenacidade, caráter e agudeza. Nestes casos a caracterização se aplica ao pensamento de vigília da pessoa; em seus estados hipnoides ela é alienada, como todos somos no sonho. Mas ao passo que nossas psicoses oníricas não influenciam nosso estado de vigília, os produtos dos estados hipnoides penetram na vida desperta como fenômenos histéricos. 


\section{Freud/Trad. Carone - Comunicação Preliminar}

\section{IV}

As mesmas explicações que estabelecemos para os sintomas histéricos crônicos podem quase ser repetidas para os ataques histéricos. Como se sabe, recebemos de Charcot uma descrição esquemática do "grande" ataque histérico, a qual reconhece quatro fases em um ataque histérico completo: 1. a fase epileptoide, 2. a fase dos grandes movimentos, 3. a fase das attitudes passionelles (fase alucinatória), 4. a fase do delírio final. Charcot deriva todas as formas do ataque histérico, que na prática são observadas com maior frequência do que o grande attaque completo, da abreviação e prolongamento, da supressão e isolamento de cada fase individual.

A explicação que ensaiamos inicia na terceira fase, das attitudes passionelles. Quando está marcada com nitidez, ela traz a reprodução de uma única recordação que foi importante para a eclosão da histeria - a recordação do grande trauma $\left(\times \alpha \tau^{\prime} \varepsilon \xi_{o} \chi \eta \nu\right)$ da chamada histeria traumática - ou a recordação de uma série de traumas interrelacionados, como aqueles subjacentes à histeria comum; ou por fim o ataque resgata aqueles acontecimentos elevados à condição de trauma por coincidirem com um momento específico de disposição.

Mas há ainda ataques que na aparência consistem apenas em fenômenos motores, aos quais falta uma phase passionelle. Se for possível reportar-se ao paciente durante estes ataques (em que ocorrem espasmos generalizados, rigidez cataléptica) ou durante um attaque de sommeil - melhor ainda, se for possível evocar o ataque sob hipnose, descobre-se que também aqui está na origem a recordação de um trauma psíquico ou de uma série de traumas, que de resto se manifesta em uma fase alucinatória. Uma moça há anos sofre de ataques com convulsões generalizadas que se poderia considerar epilépticas, como de fato o foram. Para o fim de um diagnóstico diferencial, ela é hipnotizada e logo recai em seu ataque. Mas ao lhe perguntarem: "o que vê agora?", ela responde: “o cão, o cão está vindo", e comprova-se realmente que o primeiro ataque do gênero surgiu após a perseguição por um cão selvagem. O êxito da terapia confirmou a seguir o diagnóstico.

Um funcionário, que se tornou histérico por causa de uma agressão de seu chefe, sofre de ataques nos quais ele tomba ao chão, vocifera e se enfurece sem articular uma 


\section{Freud/Trad. Carone - Comunicação Preliminar}

só palavra ou dar sinais de uma alucinação. Provoca-se o ataque na hipnose, e o paciente agora indica que está revivendo a cena na qual o patrão o insulta na rua e o atinge com um bastão. Alguns dias depois ele retorna, queixando-se por ter vivido novamente o mesmo ataque, e desta vez a hipnose atesta que ele viveu a cena que de fato se vinculava à eclosão da doença: a cena no tribunal, quando não conseguiu obter reparação pela agressão, etc.

No mais, as recordações que emergem ou podem ser despertadas nos ataques histéricos também correspondem às circunstâncias que se apresentaram para nós como fundamentos dos sintomas histéricos crônicos. A exemplo destes, as recordações estão referidas a traumas psíquicos que escaparam à resolução por ab-reação ou pelo trabalho associativo do pensamento; a exemplo destes, a recordação integral ou seus componentes essenciais faltam à capacidade de recordar da consciência normal e provam pertencer ao conteúdo ideativo dos estados hipnoides de consciência com associação restrita. E por fim, elas também permitem o teste terapêutico. Nossas observações muitas vezes nos ensinaram que uma recordação deste tipo, que até então havia provocado ataques, não pode mais provocá-los caso seja conduzida na hipnose à reação e correção associativa.

Os fenômenos motores do ataque histérico podem ser interpretados em parte como formas universais de reação do afeto concomitante à recordação (como sacudir braços e pernas, algo que até os bebês fazem), em parte como movimentos que expressam diretamente esta recordação; por outra parte eles escapam a esta explicação, a exemplo dos estigmas histéricos em sintomas crônicos.

É possível ainda obter uma apreciação particular do ataque histérico se considerarmos a teoria anteriormente mencionada, segundo a qual nos casos de histeria existem grupos de ideias surgidos em estados hipnoides, excluídos do contato associativo com outros grupos mas associáveis entre si, e que representam o rudimento ora mais ora menos organizado de uma segunda consciência, de uma condition seconde. Um sintoma histérico crônico corresponde, desse modo, a uma penetração deste segundo estado na inervação corporal geralmente controlada pela consciência normal; entretanto, um ataque histérico sinaliza uma maior organização deste segundo estado e, sendo recente, significa um momento no qual esta consciência hipnoide tomou posse de 


\section{Freud/Trad. Carone - Comunicação Preliminar}

toda a existência, e portanto uma histeria aguda; mas se for recorrente, o ataque que contém a recordação significa o retorno desta recordação. Charcot já expressou a ideia de que o ataque histérico pudesse ser o rudimento de uma condition seconde. Durante o ataque, o domínio da inervação corporal transferiu-se integralmente para a consciência hipnoide. Como já mostram experiências conhecidas, nestes casos a consciência normal não é integralmente reprimida; pode até perceber os fenômenos motores do ataque, enquanto os processos psíquicos ligados a ele escapam ao seu conhecimento.

Sabemos que o percurso típico de uma histeria grave é no início composto pela formação de um conteúdo ideativo em estados hipnoides que a seguir, suficientemente ampliado, apodera-se da inervação corporal e da existência do paciente em um período de "histeria aguda", engendra sintomas crônicos e ataques e depois é neutralizado, à exceção de alguns restos. Se a pessoa normal recupera o domínio, retorna nos ataques histéricos o que havia sobrevivido dos estados hipnoides, reconduzindo periodicamente a pessoa a estados similares, que por sua vez são suscetíveis a influências e à incorporação de traumas. Estabelece-se em seguida uma espécie de equilíbrio entre os grupos psíquicos unificados em uma mesma pessoa: ataque e vida normal caminham lado a lado sem exercer influência sobre o outro. $O$ ataque passa a ocorrer espontaneamente, como nos chegam normalmente as recordações, mas pode igualmente ser provocado, como são despertadas todas as recordações segundo as leis da associação. $\mathrm{O}$ ataque é provocado ou pela estimulação de uma zona histerógena ou por uma nova experiência que reverbera a experiência patógena por semelhança. Esperamos indicar, se possível, que não há diferença essencial entre estas duas condições tão diversas na aparência, que em ambos os casos toca-se em uma recordação hiperestésica. Em outros casos este equilíbrio é muito frágil, o ataque surge como manifestação do resto da consciência hipnoide toda vez que estiverem esgotadas a força ou a aptidão da pessoa normal. É bem possível que em tais casos o ataque, despido de seu significado original, venha a retornar como uma reação motora inócua.

As condições determinantes para que uma individualidade histérica se manifeste em ataques, sintomas crônicos ou em uma combinação de ambos são tarefas para uma investigação futura. 
Compreende-se agora como se dá a ação curativa do método psicoterapêutico que apresentamos. Ele suspende a eficácia da ideia que não foi ab-reagida na origem ao permitir que seu afeto aprisionado siga o fluxo pela fala e ao conduzir a ideia à correção associativa, movendo-a para a consciência normal (na hipnose leve) ou suspendendo-a pela sugestão médica, como ocorre no sonambulismo com amnésia.

Consideramos expressivo o benefício terapêutico do uso deste procedimento. Evidentemente não curamos a histeria, por representar uma disposição, e nada obtemos contra o retorno de estado hipnoides. Mesmo durante o estágio produtivo de uma histeria aguda, nosso procedimento não pode impedir que fenômenos vencidos a grande custo logo sejam substituídos por novos. Mas, transcorrido este estágio agudo e subsistindo seus restos (como sintomas histéricos crônicos e ataques), nosso procedimento, por ser radical, supera-os com frequência e de modo definitivo, e nos parece ultrapassar amplamente a eficácia da suspensão direta por sugestão, tal como praticada atualmente pelos psicoterapeutas.

Se, ao descobrir o mecanismo psíquico dos fenômenos histéricos, demos um passo adiante na trilha que Charcot iniciou com grande êxito ao esclarecer e reproduzir experimentalmente as paralisias histerotraumáticas, não ocultamos entretanto que por esta via somente o mecanismo dos sintomas histéricos aproximou-se de nosso conhecimento, e não as causas internas da histeria. Apenas tangenciamos a etiologia da histeria, e na verdade pudemos iluminar somente as causas das formas adquiridas, o significado do fator acidental para a neurose.

Viena, em Dezembro de 1892.

\footnotetext{
NOTAS DO TRADUTOR

${ }^{i}$ Traduzido de "Über den psychischen Mechanismus hysterischer Phänomene (Vorläufige Mitteilung)", em BREUER, J. e FREUD, S. Studien über Hysterie. Frankfurt am Main, S. Fischer Verlag, 1992, pp. 2742. Foram consultadas quatro traduções estrangeiras: Studies on Hysteria. London, Hogarth Press, 1955. Translated by James Strachey. Studies in Hysteria. London, Penguin Classics, 2002. Translated by Nicola Luckhurst. Études sur l'hysterie. Paris, PUF, 1956, traduit de l'allemand par Anne Berman. La histeria. Sigmund Freud, Obras Completas, vol. X. Buenos Aires, Santiago Rueda Editor, 1952. Traducción del alemán por Luiz López-Ballesteros y de Torres.
} 


\section{Freud/Trad. Carone - Comunicação Preliminar}

As traduções são indicadas nas notas pelas abreviações JS (James Strachey), NL (Nicola Luckhurst) e AB (Anne Berman), e BT (Ballesteros y de Torres).

ii "causa precipitadora": Veranlassung. "precipitating cause" (JS/NL), "la cause" (AB), "motivación” (BT; aparece como único equivalente para os substantivos "Veranlassung" e "Vorgang"). Foi seguida aqui a solução dos tradutores ingleses, que favorece a distinção entre Ursache (causa) e Veranlassung, termo que designa o motivo ou ocasião que produziu um evento determinado.

iii “recalcado": unterdrückt. "suppressed” (JS/NL), “etouffée” (AB), “retenido” (BT). Na psicanálise pósfreudiana, bem como em diversas interpretações da obra de Freud, ficou consagrada uma distinção entre os mecanismos da Verdrängung, (traduzida como "repressão") e da Unterdrückung, (que aqui aparece como "recalque"). Acompanhei nestes dois casos a solução proposta por Marilene Carone, para quem " 'Verdrängung' se ajusta perfeitamente bem a 'repressão', pois o que sobressai como fundamental é o conceito de Drang (ímpeto, furor, pressão)" (CARONE 1983: 128). Se a fronteira entre os conceitos é pouco distinta mesmo nos textos maduros de Freud, neste caso ela possui valor ainda mais limitado: Freud e Breuer os utilizam quase como sinônimos para retratar a expulsão ou o afastamento de um certo conteúdo para fora da consciência normal.

iv "eliminado pela fala": ausgesprochen, "verbal utterance” (JS), “is talked through"” (NL), "verbalement traduit" $(A B)$, "expresado"” $(B T)$. As duas principais acepções para o substantivo Aussprache são "pronúncia" (ou "enunciação") e também "expressão". No entanto, o recorrente emprego de aspas tanto para este substantivo quanto para o verbo "aussprechen" ("pronunciar" ou "expressar") - a exemplo das palavras "esquecimento", "abreação" e "catártico" - sinaliza que o termo está sendo empregado em um sentido incomum ou inusitado. Ora, Aussprache é composto pelo substantivo Sprache (fala, língua) e acrescida pelo prefixo aus, que exprime o movimento que parte de dentro para fora. Os pacientes histéricos são instados por Freud e Breuer a libertar-se de recordações e afetos que ficaram "presas", descarregando-as por intermédio da palavra. Parece-me que as expressões "eliminar pela fala" ou "eliminação pela fala" dão maior relevo ao uso da fala como uma forma eficaz para a descarga de uma energia acumulada, mais do que como via para a elaboração de um conflito. Cabe lembrar ainda que Aussprechen é o termo do qual Breuer se serve como equivalente para a talking cure mencionada por sua paciente Anna O, no capítulo seguinte do livro.

v "desgaste": Usur, “wearing away process" (JS), "erosion” (NL), "usure” (AB), “desgaste” (BT). A "usura" está em sua origem vinculada à corrosão de algo que transita de modo excessivo - como o dinheiro usado para empréstimos. Uma recordação se torna traumática precisamente quando é posta "fora de circulação" pela consciência, mas o termo é cada vez menos corrente no português.

vi "botar tudo para fora, aliviar o peito": sich austoben, ausweinen, 'to cry oneself out', and to 'blow off steam' (JS); 'to let off steam', 'to cry one's eyes out' (NL), "se soulager par les larmes, décharger sa colère" $(A B)$. Ballesteros y de Torres não traduz a oração iniciada em "nossa linguagem". No lugar de versões que se ativessem ao significado estrito destas expressões ("debater-se descontroladamente" ou "enfurecer-se"; "derramar-se em lágrimas") busquei no uso idiomático do português termos que descrevessem uma forte reação emocional. Observemos que Breuer e Freud as empregam com o desembaraço de quem utiliza expressões de uso corrente que podem ser compreendidas imediatamente pelos leitores.

vii "injúria”: Kränkung; “mortification" (JS), “injury” (NL), “affection” (AB). Esta frase não aparece na tradução de Ballesteros y de Torres. O termo original guarda uma conexão com Kranke (doente) e Krankheit (doença). Em português, "injúria" recobre o mesmo campo semântico da palavra alemã, denotando as ações de ofender, magoar, dirigir insulto a uma pessoa ou causar-lhe algum dano. 
viii "complexo de associação": Assoziationskomplex; "complex of associations" (JS), "complex of association" (NL) "complexe des associations" (AB), "complejo de la asociación" (BT). A presença do termo "associação" não deve nos fazer supor que Freud e Breuer já estivessem próximos do método da livre associação (freier Einfall). Lembremos que na língua alemã o termo Assoziation correponde somente à associação compreendida como categoria geral, ao conceito de uma conexão entre dois ou mais elementos de uma série, e não à ideia ou imagem que ocorre a uma pessoa, para a qual Freud reservará posteriormente o termo Einfall.

ix "algo que ele intencionalmente reprimia, inibia e recalcava de seu pensamento consciente": die er darum absichtlich aus seinem bewussten Denken verdrängte, hemmte und unterdrückte; "repressed from his conscious thought and inhibited and suppressed" (JS); "reppressed, inhibited and suppressed from his conscious thought" (NL) "qu'intentionnellement il maintenait, repoussait, refoulait, hors de sa pensée consciente" (AB), "las expulsaba intencionadamente de su pensamiento consciente" (BT). Ver acima a nota à tradução do termo unterdrückt.

x o terreno no qual o afeto assenta a recordação patógena: den Boden.., auf welchem der Affekt die pathogene Erinnerung... ansiedelt; "the soil in which the affect plants the pathogenic memory" (JS); "the ground in which the affect establishes the pathogenic memory" $(N L)$ "ils fournissent le terrain sur lequel l'affect va édifier le souvenir pathogène" (AB), "el terreno en el que el afecto instala al recuerdo patógeno" (BT). O recurso a metáforas para a descrição de processos psicológicos é familiar a qualquer leitor de Freud. Mas nem sempre se concede atenção ao laço entre as construções metafóricas e a terminologia da psicanálise - isto é à apropriação da linguagem metafórica pelo discurso científico. Para lembrarmos a expressão da tradutora britânica Joyce Crick (CRICK 2003: xxxii), tão importantes quanto as metáforas de Freud são as suas metóforas latentes - as sucessões de imagens e comparações que ao fim se cristalizam em uma linguagem teorica. Se, como querem Breuer e Freud, o trauma psíquico "age à maneira de um corpo estranho" - expulso para fora do "espaço" da consciência - é natural que ilustrem a formação deste trauma pela analogia do terreno no qual el se assenta.

\section{Referências Bibliográficas}

BREUER, J. e FREUD, S. Studien über Hysterie. Frankfurt am Main, S. Fischer Verlag, 1992. Studies on Hysteria. London, Hogarth Press, 1955. Translated by James Strachey. . Studies in Hysteria. London, Penguin Classics, 2002. Translated by Nicola Luckhurst. .Études sur l'hysterie. Paris, PUF, 1956, Traduit de l'allemand par Anne Berman.

La histeria. Sigmund Freud, Obras Completas, vol. X. Buenos Aires, Santiago Rueda Editor, 1952. Traducción del alemán por Luiz López-Ballesteros y de Torres.

Estudos sobre a histeria. Edição Standard das obras psicológicas completas de Sigmund Freud, vol. 2, Rio de Janeiro, Imago, 1990. Tradução coordenada por Jayme Salomão.

CARONE, M. "A negação: um claro enigma de Freud", Revista Discurso no. 15, São Paulo, 1983.

CRICK, J. "Translator's Preface", em FREUD, S. Jokes and its relation to the Unconscious. London, Penguin Classics, 2003, pp. xxix-xlii. 